\title{
CORRIGENDUM
}

\section{New method to compute the missed approach fuel consumption and its emissions - CORRIGENDUM}

\section{A. Murrieta-Mendoza and R. Mihaela Botez}

DOI: 10.1017/aer.2016.37, Published online: 10 May 2016

Steven Ford was omitted from the list of authors in the article by Murrieta-Mendoza ${ }^{(1)}$. The correct authorship is:

A. Murrieta-Mendoza, R. Mihaela Botez and S. Ford

The article has now been updated with the correct authorship; this change has been made to the online version only.

\section{REFERENCE}

1. Murrieta-Mendoza, A. and Minaela, Botez, R. New method to compute the missed approach fuel consumption and its emissions, Aeronautical J, 2016, 120, pp 910-929. 